\title{
Development and optimization of in-situ forming microparticles for long term controlled delivery of deslorelin acetate
}

\author{
Deepak N. Kapoor ${ }^{1 *}$, Om Prakash Katare ${ }^{2}$, Hemlata Kaurav ${ }^{1}$, Sanju Dhawan ${ }^{2}$ \\ ${ }^{1}$ School of Pharmaceutical Sciences, Shoolini University of Biotechnology and Management Sciences, Solan, H.P., India. \\ ${ }^{2}$ UGC-CAS, University Institute of Pharmaceutical Sciences, Panjab University, Chandigarh, India.
}

\begin{tabular}{|c|c|}
\hline ARTICLE INFO & ABSTRACT \\
\hline Article history: & \multirow{8}{*}{$\begin{array}{l}\text { Deslorelin is a nonapeptide analogue of the natural gonadotropin releasing hormone or luteinizing hormone } \\
\text { releasing hormone used to treat prostate cancer, endometriosis and uterine fibroids. In-situ forming } \\
\text { microparticles were developed for deslorelin using smart, biodegradable polymer i.e. PLGA. Response surface, } \\
\text { I-optimal design were used to design, formulate and characterize different formulations of deslorelin. To } \\
\text { determine the optimized formulation, numerical and graphical optimization techniques were employed. The } \\
\text { resulting optimized formulation was evaluated for other physicochemical parameters viz., rheology, particle size } \\
\text { distribution, surface morphology of the particles, peptide conformation stability in the formulation and stability } \\
\text { study at different environmental conditions. It was concluded that the optimized deslorelin acetate ISFM } \\
\text { formulation effectively extended the peptide release for } 30 \text { days while maintaining its conformational stability } \\
\text { during the period of study. The optimized ISFM formulation was found to be stable at } 5^{\circ} \mathrm{C} \pm 2^{\circ} \mathrm{C} \text { and } 25^{\circ} \mathrm{C} \pm \\
2^{\circ} \mathrm{C} \text { during } 6 \text { months stability studies. }\end{array}$} \\
\hline Received on & \\
\hline Accepted on: 3 & \\
\hline Available online: $28 / 01 / 2018$ & \\
\hline Key words: & \\
\hline PLGA, Implants, Optimal & \\
\hline Design, Peptide and Protein & \\
\hline Delivery. & \\
\hline
\end{tabular}

\section{INTRODUCTION}

Unlike conventional small molecules, therapeutic proteins are difficult to be administered orally because they are liable to degradation by the harsh gastric environment, hepatic metabolism and short half-lives thereby necessitating frequent administration of high doses by parenteral route (Cleland et al., 2001; Fu et al., 2000; Robinson and Talmadge, 2002). This may lead to major compliance issues in case of geriatric and pediatric patients on replacement therapy. To improve the patient compliance and convenience, prefilled syringes, needleless injectors, auto injectors, pen devices and syringe injectors have been introduced in the market (Arslanoglu et al., 2000; Oberye et al., 2000). However, even these modified and improved versions have their own limitations like higher cost and complex manufacturing process. Moreover, they do not address the requirement for decrease in the dosing frequency.

* Corresponding Author

Deepak N Kapoor, School of Pharmaceutical Sciences, Shoolini

University of Biotechnology and Management Sciences, Solan-173212,

H.P., India. Email: deepakpharmatech@gmail.com
Deslorelin is a luteinizing hormone releasing hormone (LHRH)/Gonadotropin releasing hormone $(\mathrm{GnRH})$ analogue which is 144 times more potent than the native LHRH/GnRH (Suprelorin, 2010). It is used to treat prostate cancer, endometriosis, uterine fibroids, precocious puberty and breast cancer (Kiesel et al., 2002). Treatment with GnRH or its agonists require long term therapy primarily by parenteral route (i.v., s.c. or i.m.) since these peptides are vulnerable to gastrointestinal peptidase degradation which makes them inappropriate for oral administration with only $0.1 \%$ bioavailability (Conn and Crowley, 1991; Chrisp and Goa, 1990). Intra-nasal administration of deslorelin is also ineffective and inconstant, with only 4 to $21 \%$ being available relative to s.c. or i.v. injection, necessitating frequent large doses (Gudmundsson et al., 1984).

Phase-sensitive, in-situ forming injectable systems can be used to achieve controlled release of peptides and proteins which works on the principle of phase inversion and utilize solvent(s) and a polymeric matrix (Okuma et al., 2001). It is prepared by dissolving biodegradable polymers in biocompatible organic solvents, forming a homogenous solution or a suspension depending on its solubility (Wang et al., 2004). 
The drug loaded suspension or solution is injected subcutaneously and forms an in-situ forming implant that slows down the drug release over an extended period of time. These systems consist of drug dissolved or dispersed in a biodegradable polymer. When liquid composition is injected by i.m. or s.c. route, diffusion of organic solvent takes place in the body fluids allowing the water to penetrate into the polymer matrix, gradually replacing the organic solvent. Consequently, phase separation and polymer precipitation takes place resulting in the formation of solid polymeric implant at the injection site which releases the drug in a controlled manner (Al-Tahami et al., 2006). Drug release from the implant thus formed is controlled by the properties of the polymer, solvent and drug. Various ISFI based peptide and protein drug delivery systems have been successfully commercialized e.g., Eligard $^{\circledR}$, an in-situ forming implant system for the controlled delivery of a protein drug leuprolide acetate used in the treatment of prostate cancer (Ravivarapu et al., 2000).

ISFI systems may however, present with some limitations such as poor injectability because of highly viscous polymer solution, burst release and poor reproducibility of the drug release because of varied injection techniques and different physiological conditions at implantable site. Thus, to overcome these drawbacks, "in-situ forming microparticles" (ISFM), another variation of an ISFI system has been reported (Kranz and Bodmeier, 2007; Kranz et al., 2008). ISFM systems are based on emulsification of a biodegradable polymer solution and a continuous oil or aqueous phase. Once injected, polymer solution droplets solidify to form microparticles in-situ. In ISFM, the viscosity of the emulsion formed is low in comparison to pure polymeric solution which reduces pain during injection and the presence of an external oil phase also reduces initial burst release. In addition, ISFM are multiparticulate systems that may reduce the morphological dissimilarities of single unit implants and release the drug in more consistent and reproducible manner (Luan et al., 2006). Thus, in-situ forming systems could be explored for controlled delivery of deslorelin acetate. Since, the normal human dose of deslorelin is low i.e., $100 \mu \mathrm{gm} /$ day, it was decided to develop ISFM system of deslorelin for long term (30 days) delivery.

\section{MATERIALS ANDMETHODS}

\section{Materials}

Deslorelin acetate was purchased from Bachem AG, Bubendorf (Switzerland). PLGA (75:25) [poly (D,L-lactide-coglycolide)] having inherent viscosity $0.55-0.75 \mathrm{dl} / \mathrm{g}$ and resorption time of 1-2 months was obtained from Lactel Absorbable Polymers, Durect Corporation (USA). DMSO (Dimethylsulfoxide), Iso propyl myristate, Peanut oil (Pharmaceutical grade), span 80 and tween 80 were procured from Loba Chemie Pvt. Ltd., Mumbai (India). Benzyl benzoate (BZ) and Benzyl alcohol (BA), Triacetin (TR) were procured from SD Fine Chem. Ltd., Mumbai (India). All other chemicals and reagents were of AR grade.

\section{Analytical method validation}

The analysis of drug during preformulation studies was carried out by UV spectroscopy. During optimization studies HPLC method was used for the analysis of deslorelin. For UV analysis, standard plot of concentration vs. absorbance for deslorelin acetate was prepared in $\mathrm{pH} 7.4$ phosphate buffer at $\lambda_{\max }$ $280 \mathrm{~nm}$. For HPLC analysis of deslorelin acetate, a modified version of previously reported HPLC method was used (Kompella and Dani, 1996; Kompella and Dani, 1997; Wood et al., 1998).

\section{Method}

The method was validated by determining linearity, accuracy, precision, LOD and LOQ.

\section{Chromatographic conditions}

A Bondapack ${ }^{\circledR} \mathrm{C}-18$ column $(250 \mathrm{x} 4 \mathrm{~mm}$ i.d. $)$ with a particle diameter of $10 \mu \mathrm{m}$ and a pore size of $125 \AA$ from Waters ${ }^{\circledR}$ was used. The mobile phase consisted of $30 \%$ acetonitrile and $70 \%$ HPLC grade water containing $0.1 \%$ trifluoroacetic acid. The flow rate was $1 \mathrm{~mL} / \mathrm{min}$ and the injection volume was $100 \mu \mathrm{L}$. The analysis was carried out at a wavelength of $220 \mathrm{~nm}$ (Kompella and Dani, 1996; Kompella and Dani, 1997; Wood et al., 1998).

\section{Standard solution preparation}

A set of 10 standard solutions containing deslorelin acetate were prepared using deslorelin acetate stock solution (1000 $\mu \mathrm{g} / \mathrm{mL})$. The diluent used was mobile phase and concentrations of prepared standard solutions were 1, 6, 15, 30, 60, 90, 120, 150, 180 and $300 \mu \mathrm{g} / \mathrm{mL}$.

\section{Validation of HPLC Method of analysis for deslorelin acetate Linearity}

Three sets of pure drug standards were prepared by dissolving deslorelin acetate in the diluent to give concentrations of $1-300 \mu \mathrm{g} / \mathrm{mL}$. The samples were analyzed by HPLC. The data was analyzed to determine whether a linear relationship existed between the absorbance and concentration over the expected range of concentrations in the analysis. Ratio of response to concentration (sensitivity) vs log of concentration was plotted to determine the linearity of the method (Kapil et al., 2009).

\section{Accuracy}

Quality control solutions of different concentrations viz., low (LQC: $15 \mu \mathrm{g} / \mathrm{mL}$ ), medium (MQC: $90 \mu \mathrm{g} / \mathrm{mL}$ ) and high (HQC: $180 \mu \mathrm{g} / \mathrm{mL}$ ) were prepared using stock solution of deslorelin acetate followed by HPLC analysis. Accuracy was measured as the percentage relative error and mean percentage recovery (Kapil et al., 2009; Kapoor et al., 2012).

\section{Precision}

The intermediate precision was assessed by analyzing three different concentrations $(15,90$ and $180 \mu \mathrm{g} / \mathrm{mL})$ of deslorelin acetate on three different days for inter day variation $(n=3)$. The precision was determined from the RSD of predicted 
concentrations that were obtained from the regression equation. The values of limit of quantitation (LOQ) and limit of detection (LOD) of deslorelin were calculated using standard calibration curve as $3.3 \sigma / \mathrm{S}$ and $10 \sigma / \mathrm{S}$, respectively, where $\mathrm{S}$ is the slope of the calibration curve and $\sigma$ is the standard deviation of the response (Kapil et al., 2009).

\section{Preparation of In-situ Forming Microparticles (ISFM) of deslorelin acetate}

Different batches using different quantities of excipients and same quantity of drug $(1 \mathrm{mg} / 100 \mathrm{mg}$ formulation) were prepared. For the preparation of different ISFM formulations, PLGA (75:25) [poly (D,L-lactide-co-glycolide)], BA:BZ (30:70) (Benzyl alcohol: Benzyl benzoate), DMTR (60:40) (Dimethyl sulfoxide: Triacetin), peanut oil, Span 80 and aluminium monostearate were selected as different components of the formulation. Oil phase 2 (a solution of deslorelin acetate and PLGA in the solvent mixture) was added drop wise from a syringe to oil phase 1 (Peanut oil containing 2\% Span 80 and 2.5\% aluminum monostearate) taken in a beaker. The mixture was continuously homogenized at $10,000 \mathrm{rpm}$, using an Ultra Turrax ${ }^{\circledR}$ for $10 \mathrm{~min}$, to form PLGA microglobules dispersed in the continuous oil phase and stabilized by Span 80 \& aluminiummonostearate. The system thus obtained was termed as an ISFM system' (Jain et al., 1998; Jain et al., 2000; Luan and Bodmeier, 2006). The capability of ISFM system to form microspheres in-situ was confirmed in phosphate buffer solution (Jain et al., 2000). The ISFM system was introduced into a $15 \mathrm{~mL}$ glass vial containing pH 7.4 phosphate buffer and $0.1 \%$ Tween 80 . A turbid white dispersion of 'suspended microparticles' was formed that was shaken on a water bath shaker at $37^{\circ} \mathrm{C}$ for $5 \mathrm{~h}$. The suspension was then filtered to separate the microparticles that were vacuum dried to obtain 'dried microspheres'.

\section{Experimental Design and Optimization Studies}

Design of Experiment (DoE) was applied to determine the quantities and number of batches required to determine the optimized deslorelin ISFM formulation. Accordingly, all the formulations were prepared, responses measured and the results analyzed using a DoE software Design Expert ${ }^{\circledR}$ ver. 8.0.1 (www.statease.com). Table 1 shows the factors and levels of the independent variables that were evaluated.

Table 1: DoE factors and levels explored to prepare deslorelin ISFM formulations.

\begin{tabular}{|c|c|c|c|c|}
\hline \multirow[t]{2}{*}{ Factors } & & \multirow[t]{2}{*}{ Type } & \multicolumn{2}{|l|}{ Levels } \\
\hline & & & L1 (-1) & L2 (+1) \\
\hline $\begin{array}{l}\text { PLGA Concentration }(\%) \\
\text { internal phase } \mathrm{O}_{2}\left(X_{I}\right)\end{array}$ & w.r.t. & eric & 15 & 25 \\
\hline $\mathrm{O}_{1} / \mathrm{O}_{2}$ w/w ratio $\left(X_{2}\right)$ & & Numeric & $1: 1$ & $2: 1$ \\
\hline Solvent type $\left(X_{3}\right)$ & & Catagoric & DMTR & BABZ \\
\hline
\end{tabular}

A Response Surface I-optimal design was employed to predict the optimal formulation. Response surface designs are applied to quantify the relationships between one or more measured responses and the vital input factors (www.statease.com). An I-optimal design seeks to minimize the integral of the prediction variance across the design space. IOptimal designs are best used with response surface analysis and experiments that include both numeric as well as catagoric factors. The design was assessed by quadratic model using the following equation:

$Y=\beta_{0}+\beta_{I} X_{1}+\beta_{2} X_{2}+\beta_{3} X_{3}+\beta_{4} X_{1} X_{2}+\beta_{5} X_{1} X_{3}+\beta_{6} X_{2} X_{3}+\beta_{7} X_{1}^{2}+$ $\beta_{8} X_{2}^{2}+\beta_{9} X_{3}^{2} \quad$... (1)

where, $Y$ is the response variable, $\beta_{0}$ the constant and $\beta_{1,} \beta_{2} \ldots \beta_{9}$ are the regression coefficients. $X_{1}, X_{2}$ and $X_{3}$ stand for the main effect, $X_{I} X_{2}, X_{I} X_{3}, X_{2} X_{3}$ are the interaction terms and show how the response changes when two factors are simultaneously changed. $X_{1}^{2}, X_{2}^{2}$ and $X_{3}^{2}$ are quadratic terms of the independent variables to evaluate the nonlinearity (Singh et al., 2004; Antony, 2003). One way ANOVA and multiple linear response analysis (MLRA) was used to generate the equation for each response parameter (Kapoor et al., 2012). Constraints for the drug release at 1 day, 14 days and 30 days were set as minimum, 40-60 (medium) and maximum, respectively.

\section{Validation of optimization results}

The optimized formulation was prepared and evaluated for different response parameters. To validate the results, practically obtained experimental values were compared with predicted values obtained by optimization technique.

\section{Evaluation of ISFM formulations \\ In vitro release studies}

ISFM equivalent to $3 \mathrm{mg}$ deslorelin acetate was injected into $10 \mathrm{~mL}$ phosphate buffer $\mathrm{pH} 7.4$, containing $0.1 \%$ sodium azide and $0.1 \%$ Tween 80 maintained at $37^{\circ} \mathrm{C}$ and shaken in a water bath shaker. Aliquots of release samples $(n=3)$ were withdrawn and replaced by fresh release media at $0.25,0.5,1,2,4$, $6,8,10,12,14,18,22,26$ and 30 days. The deslorelin concentration in the withdrawn samples was determined by HPLC method. Cumulative percent drug release was calculated after correcting the values for withdrawn sample (Singh and Singh, 1998). The in vitro drug release data obtained from ISFM systems were fitted to various release kinetic models viz., zero-order, firstorder, Hixson-Crowell, Higuchi and Korsemeyer-Peppas mathematical models (Higuchi, 1963; Korsemeyer et al., 1983; Peppas and Sahlin, 1989).

\section{Rheological studies}

Rheological studies are mainly determine the relationship between viscosity, shear stress and stress strain (Plaizier et al., 1989). The shear strain exerted by the formulations due to the application of shear stress was calculated using equation (Dhawan et al., 2011):

$$
\text { Viscosity }=\frac{\text { Shear stress }}{\text { Shear strain }}
$$




\section{Drug loading and encapsulation efficiency}

Weighed quantities of dried microparticles were solubilize in methylene chloride under vigorous vortexing. Phosphate buffer $\mathrm{pH} 7.4$ was added to the methylene chloride and the samples were agitated to extract drug in the aqueous phase and to evaporate methylene chloride. The precipitated polymer in the buffer was separated by ultracentrifugation at 10,000 rpm and the drug in the aqueous supernatant was analyzed using UV spectrophotometer (Koushik et al., 2004). The percent encapsulation efficiency was calculated using the following equation:

Encapsulation Efficiency $(\%)=\frac{\text { Actual Drug Content }}{\text { Theoretical Drug Content }} \times 100$

\section{Particle size distribution}

Particle size distribution of formed, suspended deslorelin microparticles was determined by using Malvern Mastersizer. Dispersion of 'suspended microparticles' was sonicated on a bath sonicator for $5 \mathrm{~min}$ to uniformly disperse the particles. The redispersed sample was used for particle size analysis.

\section{Surface morphology}

The shape and surface characteristics of ISFM was assessed using images obtained by optical microscopy and transmission electron microscopy (Jain et al., 2000). For transmission electron microscopy (TEM), a drop of suspended microparticles was placed on copper electron microscopy grid. Excess sample was removed by using filter paper after $30 \mathrm{sec}$. The sample was air dried and examined by TEM (Shen et al., 2008; Bansal et al., 2011).

\section{DSC and FTIR}

The Differential Scanning Calorimetry (DSC) analysis for different samples was carried out to determine glass transition temperature $(\mathrm{Tg})$. The FTIR spectra of different samples were obtained in the frequency range of $500-4000 \mathrm{~cm}^{-1}$ which were compared with FTIR spectra of pure drug to determine any interaction of the drug with other excipients used in the formulation.

\section{Conformation stability by CD spectroscopy (Circular Dichroism)}

The samples collected from in vitro release studies were screened for conformational stability using CD spectroscopy (Kapil et al., 2009). Spectra were collected at $25^{\circ} \mathrm{C}$ using a $0.1 \mathrm{~cm}$ cell over the wavelength range of $190-250 \mathrm{~nm}$. The absorbance obtained was plotted against the respective wavelength for both the samples and the plots were compared for conformational stability of proteins (Dhawan et al., 2009; Dhawan et al., 2011).

\section{Stability studies}

Stability study of the final formulation was carried out at accelerated and long term conditions of temperature and humidity $\left(25^{\circ} \mathrm{C} \pm 2^{\circ} \mathrm{C} / 60 \% \pm 5 \% \mathrm{RH} ; 5^{\circ} \mathrm{C} \pm 2^{\circ} \mathrm{C}\right.$ ) for 6 months (WHO) (ICHQ1F). At predetermined intervals (0, 1, 3 and 6 months), samples were withdrawn and analyzed for various performance parameters i.e., drug content, viscosity and drug release (Kapoor et al., 2012).

\section{RESULTS AND DISCUSSION}

Validation of HPLC method of analysis for deslorelin acetate

Linear mathematical relationship was observed between drug concentration vs AUC. At all the drug concentration levels studied (1-300 $\mu \mathrm{g} / \mathrm{mL}$ ), the ranges of standard deviation (1863 to $1456073)$ and the relative standard deviation (0.57 to 2.54) for AUC were found to be satisfactory, indicating good repeatability. The values of predicted concentrations were nearly matching with that of the actual concentrations. Linearity of the method was established by plotting the ratio of response: concentration (i.e., sensitivity) vs. log of concentration (Figure 1) (Kapil et al., 2013). All the points were found within $\pm 5 \%$ of the average value. Accuracy data was obtained for validation of the analytical procedure.

The prediction error (i.e., bias) values were found between $-0.90 \%$ and $2.17 \%$ for the 3 levels of concentration studied, indicating high accuracy of the methodology employed. The high mean percent recovery values (98-102\%), corresponding low SD values $(\leq 1.45)$ and low RSD $(\leq 1.42)$ observed during the studies also verified high accuracy of the analytical method.

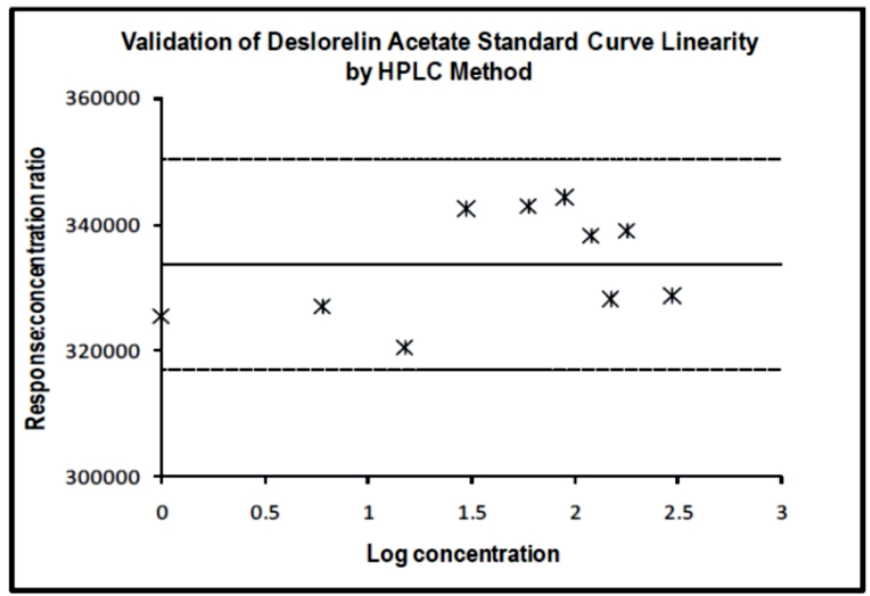

Fig. 1: Plot of $\log$ deslorelin acetate concentration vs response-concentration ratio for linearity validation of HPLC method of analysis for deslorelin acetate.

The RSD of the concentrations predicted from the regression equation was taken as precision value. The RSD values ranged between 0.57 and $2.56 \%$ in the repeatability study. Intermediate precision expresses within-laboratory variation on different days. In all the cases, low magnitude of RSD observed in the studies construe good repeatability and precision of the method. The values of LOD and LOQ for deslorelin acetate by HPLC method were found to be 0.020 and $0.057 \mu \mathrm{g} / \mathrm{mL}$, respectively, showing good sensitivity of the method even at submicrogram levels. 
Table 2: Response variables $Y_{1}, Y_{2}$ and $Y_{3}$ for different factor combinations of deslorelin ISFM formulations prepared as per I-optimal RSM design.

\begin{tabular}{|c|c|c|c|c|c|c|}
\hline Run / & Factor $1\left(X_{1}\right)$ & Factor $2\left(X_{2}\right)$ & Factor $3\left(X_{3}\right)$ & Response $1\left(Y_{1}\right)$ & Response $2\left(Y_{2}\right)$ & Response $3\left(Y_{3}\right)$ \\
\hline Batch no. & PLGA (\%) & $\mathrm{O}_{1} / \mathrm{O}_{2}$ (wt. ratio) & Solvent & Release 1 day (\%) & Release 14 days (\%) & Release 30 days (\%) \\
\hline DM1 & 15 & 1 & DMTR & 15.54 & 76.32 & 98.09 \\
\hline DM2 & 20 & 1 & DMTR & 13.68 & 61.96 & 87.02 \\
\hline DM3 & 25 & 1 & DMTR & 9.55 & 55.47 & 79.31 \\
\hline DM4 & 15 & 1.5 & DMTR & 12.19 & 69.48 & 93.52 \\
\hline DM5 & 25 & 1.5 & DMTR & 7.99 & 51.68 & 80.37 \\
\hline DM6 & 15 & 2 & DMTR & 10.34 & 68.97 & 91.18 \\
\hline DM7 & 20 & 2 & DMTR & 9.00 & 57.63 & 83.12 \\
\hline DM8 & 25 & 2 & DMTR & 6.01 & 47.11 & 71.55 \\
\hline DM9 & 15 & 1 & BABZ & 12.74 & 63.73 & 95.35 \\
\hline DM10 & 25 & 1 & BABZ & 7.8 & 44.31 & 68.18 \\
\hline DM11 & 20 & 1.5 & BABZ & 8.64 & 52.24 & 85.29 \\
\hline DM12 & 15 & 2 & BABZ & 9.17 & 59.21 & 89.32 \\
\hline DM13 & 25 & 2 & BABZ & 4.68 & 37.19 & 54.79 \\
\hline
\end{tabular}

Table 3: Statistical parameters for different response variables obtained by ANOVA and multi linear regression analysis.

\begin{tabular}{|c|c|c|c|c|c|c|}
\hline \multirow{3}{*}{$\begin{array}{c}\begin{array}{c}\text { Coefficients } \\
\text { (Factor) }\end{array} \\
\beta_{0}(\text { Intercept })\end{array}$} & \multicolumn{6}{|c|}{ Polynomial coefficients of various response variables } \\
\hline & \multicolumn{2}{|c|}{ Release 1 day $\left(Y_{1}\right)$} & \multicolumn{2}{|c|}{ Release 14 days $\left(Y_{2}\right)$} & \multicolumn{2}{|c|}{ Release 30 days $\left(Y_{3}\right)$} \\
\hline & 9.84 & $(p<0.0001)$ & 56.35 & $(p<0.0001)$ & 86.66 & $(p<0.0001)$ \\
\hline$\beta_{1}\left(X_{1:} P L G A\right)$ & -2.38 & $(p<0.0001)$ & -10.13 & $(p<0.0001)$ & -12.12 & $(p<0.0001)$ \\
\hline$\beta_{2}\left(X_{2:} O 1 / O 2\right)$ & -1.84 & $(p<0.0001)$ & -2.99 & $(p<0.0001)$ & -3.8 & $(p=0.0002)$ \\
\hline$\beta_{3}\left(X_{3:}\right.$ Solvent $)$ & -0.96 & $(p<0.0001)$ & -4.72 & $(p<0.0001)$ & -3.48 & $(p=0.0002)$ \\
\hline$\beta_{4}\left(X_{1} X_{2}\right)$ & 0.25 & $(p=0.0518)$ & & -- & -0.83 & $(p=0.2248)$ \\
\hline$\beta_{5}\left(X_{1} X_{3}\right)$ & 0.041 & $(p=0.6952)$ & & --- & -3.53 & $(p=0.0003)$ \\
\hline$\beta_{6}\left(X_{2} X_{3}\right)$ & 0.37 & $(p=0.0069)$ & & --- & -0.7 & $(p=0.2649)$ \\
\hline$\beta_{7}\left(X_{I}^{2}\right)$ & -0.83 & $(p=0.0101)$ & & --- & -2.157 & $(p=0.1708)$ \\
\hline$\beta_{8}\left(X_{2}^{2}\right)$ & 0.51 & $(p=0.0747)$ & & --- & -4.027 & $(p=0.0227)$ \\
\hline $\mathrm{R}^{2}$ & \multicolumn{2}{|c|}{0.9921} & \multicolumn{2}{|c|}{0.9869} & \multicolumn{2}{|c|}{0.9873} \\
\hline Adj. $\mathrm{R}^{2}$ & \multicolumn{2}{|c|}{0.9843} & \multicolumn{2}{|c|}{0.9839} & \multicolumn{2}{|c|}{0.9746} \\
\hline Pred. $\mathrm{R}^{2}$ & \multicolumn{2}{|c|}{0.9621} & \multicolumn{2}{|c|}{0.9773} & \multicolumn{2}{|c|}{0.9255} \\
\hline Adeq. Precision & \multicolumn{2}{|c|}{37.628} & \multicolumn{2}{|c|}{52.318} & \multicolumn{2}{|c|}{25.597} \\
\hline $\begin{array}{c}\text { Lack of Fit } \\
\text { Model }\end{array}$ & $\mathrm{F}=1.29$ & $(p=0.4052)$ & $\mathrm{F}=0.95$ & $(p=0.5683)$ & $\mathrm{F}=5.78$ & $(p=0.588)$ \\
\hline Linear & \multicolumn{2}{|c|}{---} & \multirow{2}{*}{\multicolumn{2}{|c|}{$\mathrm{F}=326.94 \quad(p<0.0001)$}} & \multicolumn{2}{|r|}{--- } \\
\hline Quadratic & $\mathrm{F}=126$. & $(p<0.0001)$ & & & $\mathrm{F}=77.6$ & $+(p<0.0001)$ \\
\hline
\end{tabular}

\section{In-situ forming microparticles (ISFM) of deslorelin acetate by Design of Experiment}

The ISFM formulations of deslorelin were prepared according to I-Optimal response surface experimental design. Different combinations of the three selected factors $X_{1}$ (PLGA concentration), $X_{2}\left[\mathrm{O}_{1}: \mathrm{O}_{2}\right.$ ratio or external $\left(\mathrm{O}_{1}\right)$ : internal $\left(\mathrm{O}_{2}\right)$ phase ratio] and $X_{3}$ (solvent type) were used to prepare 13 different ISFM formulations. The responses $Y_{1}$ (percent drug release at 1day), $Y_{2}$ (percent drug release at 14 days) and $Y_{3}$ (percent drug release at 30 days) were determined by carrying out percent drug release studies of the prepared formulations. The responses obtained for all the factor combinations are shown in Table 2.

The model analysis values are given in Table 3 . The models found suitable for the response variables $Y_{1}, Y_{2}$ and $Y_{3}$ were quadratic $(p<0.0001)$, linear $(p<0.0001)$ and quadratic $(p<0.0001)$, regression models with $\mathrm{R}^{2}$ values, respectively. The selected model was found to be valid as all the lack of fit values were insignificant ( $p>0.05$ ) (Kapoor et al., 2012). The closeness of adjusted $\mathrm{R}^{2}$ $(0.9843,0.9839,0.9746)$ and predicted $R^{2}(0.9621,0.9773,0.9255)$ to actual model $\mathrm{R}^{2}(0.9921,0.9869$ and 0.9873$)$ also indicated the goodness of fit to the data. Coefficient terms of various factors required to obtain polynomial equations for the three response variables are given in Table 3.
The fitting of terms in the polynomial equation indicated that the model was significant and would navigate effectively through the design space. The response surface 3D graphs were plotted to study the effect of factors PLGA $\left(\mathrm{X}_{1}\right)$ and $\mathrm{O}_{1} / \mathrm{O}_{2}\left(\mathrm{X}_{2}\right)$ on response variables $\mathrm{Y}_{1}, \mathrm{Y}_{2}$ and $\mathrm{Y}_{3}$ for both categorical factors viz. DMTR and BABZ. Fig. 2 (a) and 2 (b) shows the representative 3D plot for effect of PLGA and $\mathrm{O}_{1} / \mathrm{O}_{2}$ on 30 days drug release with solvent systems BABZ \& DMTR respectively. The plots indicate that as the PLGA concentration and $\mathrm{O}_{1} / \mathrm{O}_{2}$ ratio increased the percent drug release decreased and as the PLGA concentration decreased and $\mathrm{O}_{1} / \mathrm{O}_{2}$ ratio increased the percent drug release increased. Additionally at the end of 30 days the release from BABZ formulation was higher as compared to DMTR formulation at higher concentration of PLGA.

Final polynomial equations for each response variable in terms of actual factors are given below:

For categorical factor DMTR:

Release 1 day $=21.39+0.70 P L G A-12.59 O_{1} / O_{2}+0.10 P L G A O_{1} / O_{2}$ - 0.04PLGA ${ }^{2}+2.04 O_{1} / O_{2}^{2}$

Release $14 d=110.56-2.03 \mathrm{PLGA}-5.99 \mathrm{O}_{1} / \mathrm{O}_{2}$

Release $30 d=53.34+2.22 P L G A+48.65 O_{1} / O_{2}-0.33 P L G A O_{1} / O_{2}$ - 0.09PLGA $A^{2}-16.07 \mathrm{O}_{1} / \mathrm{O}_{2}^{2} \ldots$ (6)

For categorical factor BABZ: 
Release $I d=16.92+0.71 P L G A-11.03 O_{1} / O_{2}+0.10 P L G A O_{1} / O_{2}-$ $0.03 P L G A^{2}+2.03 O_{1} / O_{2}^{2} \quad \ldots(7)$

Release $14 d=101.12-2.03 \mathrm{PLGA}-5.99 \mathrm{O}_{1} / \mathrm{O}_{2}$

Release $30 \mathrm{~d}=78.80+0.80 \mathrm{PLGA}+45.83 \mathrm{O}_{1} / \mathrm{O}_{2}-0.33 \mathrm{PLGAO}_{1} / \mathrm{O}_{2}$ - 0.09PLGA ${ }^{2}-16.07 O_{1} / O_{2}^{2} \quad \ldots$ (9)

Finally, the model analysis data showed that the selected design, factors and responses were suitable and significant (Kapoor et al., 2012).

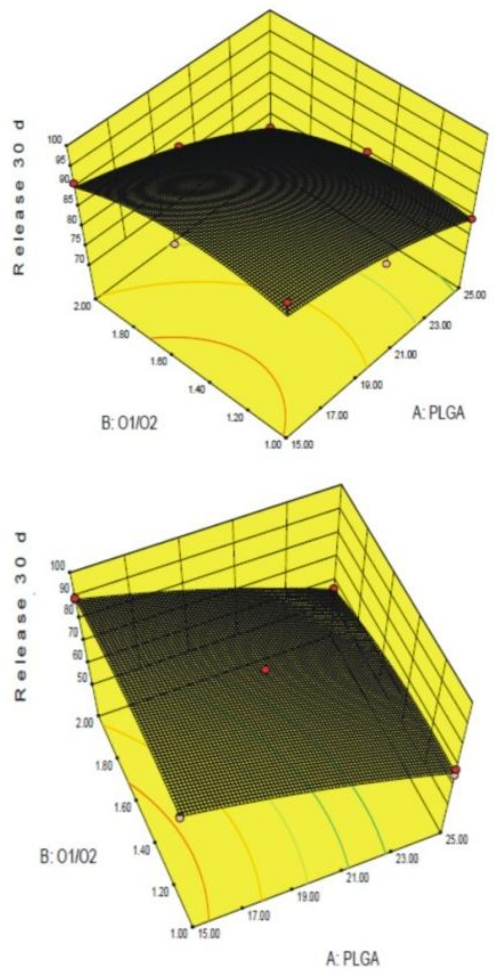

Fig. 2 (a): 3-D plots showing the effect of factors PLGA and O1/O2 ratio on response variables $\mathrm{Y} 3$ (release at 30 days) with $\mathrm{BABZ}$ as categorical factor. Fig. 2(b). 3-D plots showing the effect of factors PLGA and $\mathrm{O} 1 / \mathrm{O} 2$ on response variables Y3 (release at 3 )

\section{In vitro drug release behavior of deslorelin ISFM formulations by mathematical modeling}

Fig. 3 shows the cumulative percent drug release profile of the prepared formulations. The cumulative percent drug release profiles of different formulations were applied to different mathematical models and analyzed for suitable drug release mechanism. To determine the mechanism of drug release from different ISFM formulations the release values were evaluated for 'goodness-of-fit' into various mathematical model equations such as zero order, first order, Higuchi matrix, Peppas and HixsonCrowell cube root equation. The $\mathrm{R}^{2}$ and $k$ values of the model equation are shown in Table 4 . The model with $\mathrm{R}^{2}$ value nearest to 1.000 was considered as the 'best-fit' model for that formulation. For Peppas model, the value of $n$ was considered to decide the release mechanism.

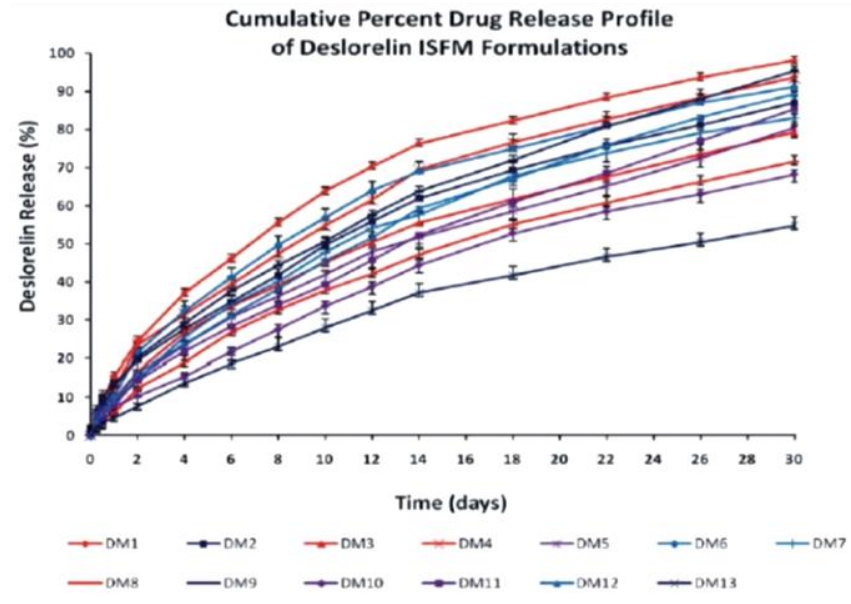

Fig. 3: Cumulative percent drug release profile of formulated deslorelin ISFM.)

In terms of $\mathrm{R}^{2}$ values, it was observed that all the formulations followed all the models except zero order. Thus, from these results it was interpreted that drug release from deslorelin ISFM formulations followed multiple mechanisms. The first order pattern indicated the porous nature of the polymer matrix involving hydrolytic kinetics. It also indicated that the drug release was dependent upon the drug concentration in the formulation, i.e., higher the concentration, faster the release. The Higuchi matrix model that was followed by almost all the formulations indicated the release of the drug dispersed in a uniform swellable polymer matrix by diffusion. For Peppas model, the formulations with $n>0.5$ indicated release by Fickian diffusion while those with $0.5<n<1$ indicated anomalous transport i.e., the release is not dependent on a single mechanism. It was found that all the formulations followed non-fickian, anomalous transport as all the values of $n$ were above 0.5. Finally, Hixson-Crowell model indicated that the release is dependent on the erosion of the polymer matrix and is also limited by drug particle dissolution.

Table 4: Mathematical model fitting values obtained from percent drug release profile of deslorelin ISFM formulations DM01 to DM13.

\begin{tabular}{|c|c|c|c|c|c|c|c|c|c|c|c|}
\hline \multirow{2}{*}{$\begin{array}{c}\text { Model } \\
\text { Batch no. }\end{array}$} & \multicolumn{2}{|c|}{ Zero order } & \multicolumn{2}{|c|}{ 1st order } & \multicolumn{2}{|c|}{ Higuchi matrix } & \multicolumn{2}{|c|}{ Hixson - Crowell } & \multicolumn{3}{|c|}{ Korsmeyer - Peppas } \\
\hline & $r^{2}$ & $k_{0}\left(h^{-1}\right)$ & $r^{2}$ & $k_{1}\left(h^{-1}\right)$ & $r^{2}$ & $k_{H}\left(h^{-1 / 2}\right)$ & $r^{2}$ & $k_{H C}\left(h^{-1 / 3}\right)$ & $r^{2}$ & $k_{K P}\left(h^{-n}\right)$ & $N$ \\
\hline DM1 & 0.8884 & 17.976 & 0.966 & 2.017 & 0.9906 & -1.323 & 0.9913 & 4.476 & 0.9917 & 1.179 & 0.59 \\
\hline DM2 & 0.9373 & 13.184 & 0.9969 & 1.977 & 0.9960 & -2.639 & 0.9914 & 4.494 & 0.9976 & 1.129 & 0.56 \\
\hline DM3 & 0.9304 & 11.395 & 0.9945 & 1.970 & 0.9973 & -3.251 & 0.9822 & 4.499 & 0.9964 & 1.016 & 0.62 \\
\hline DM4 & 0.9189 & 14.157 & 0.9916 & 1.996 & 0.9945 & -3.702 & 0.9926 & 4.507 & 0.9887 & 1.079 & 0.64 \\
\hline DM5 & 0.9516 & 9.308 & 0.9926 & 1.984 & 0.9953 & -4.923 & 0.9903 & 4.542 & 0.9961 & 0.934 & 0.67 \\
\hline DM6 & 0.9014 & 14.913 & 0.9968 & 1.978 & 0.9919 & -2.921 & 0.9836 & 4.473 & 0.9895 & 1.097 & 0.63 \\
\hline DM7 & 0.9369 & 11.153 & 0.9988 & 1.980 & 0.9932 & -4.483 & 0.9884 & 4.518 & 0.9911 & 1.044 & 0.61 \\
\hline DM8 & 0.9539 & 7.622 & 0.9972 & 1.983 & 0.9925 & -5.439 & 0.9885 & 4.554 & 0.9945 & 0.863 & 0.69 \\
\hline DM9 & 0.9490 & 12.486 & 0.9555 & 2.021 & 0.9970 & -4.557 & 0.9923 & 4.560 & 0.9964 & 1.080 & 0.62 \\
\hline DM10 & 0.9681 & 6.024 & 0.9976 & 1.989 & 0.9824 & -6.128 & 0.9921 & 4.579 & 0.9948 & 0.829 & 0.69 \\
\hline DM11 & 0.9774 & 8.046 & 0.9823 & 2.004 & 0.9848 & -6.287 & 0.9963 & 4.586 & 0.9956 & 0.988 & 0.62 \\
\hline DM12 & 0.9626 & 9.257 & 0.9878 & 2.009 & 0.9906 & -6.723 & 0.9984 & 4.581 & 0.951 & 1.347 & 0.46 \\
\hline DM13 & 0.9593 & 5.194 & 0.9893 & 1.984 & 0.9868 & -4.744 & 0.9813 & 4.575 & 0.9948 & 0.734 & 0.69 \\
\hline
\end{tabular}




\section{Determination of optimal formulation}

Numerical and graphical optimization techniques were used to determine the optimized formulation. The constraints of $\mathrm{X}$ and $\mathrm{Y}$ variables were adjusted to anticipated goals and examined throughout the experimental domain to determine the formulations achieving values nearest to the desired goals. Table 5 presents the constraints, the resulting optimized solutions, and formulation compositions with corresponding response and desirability values. The results obtained by numeric optimization present the four best solutions for two catagoric factors, DMTR and BABZ. The solutions achieve the goal of maximum overall release and minimum burst release at low to intermediate levels of PLGA (15 to 20 ) and $\mathrm{O}_{1} / \mathrm{O}_{2}$ ratio (1.7 to 2 ). Among the four solutions, solution 1 and 3 were selected because solution 1 contains BABZ as solvent and provides higher percent drug release and desirability as compared to solution 2 . Solution 3 was selected as it contained DMTR as solvent and had higher release and desirability as compared to solution 4. Finally, the formulations corresponding to solution 1 and 3 were selected as the optimum formulation which had the values of response variables in the desired range with desirability (Kapoor et al., 2012).

Similar constraints were applied to graphically determine the optimal formulation. The results are shown as overlay plots in Figures 4 (a) and (b). These plots confirmed the results obtained by numerical optimization and graphically showed the exact location of solution 1 and solution 3in the experimental domain.
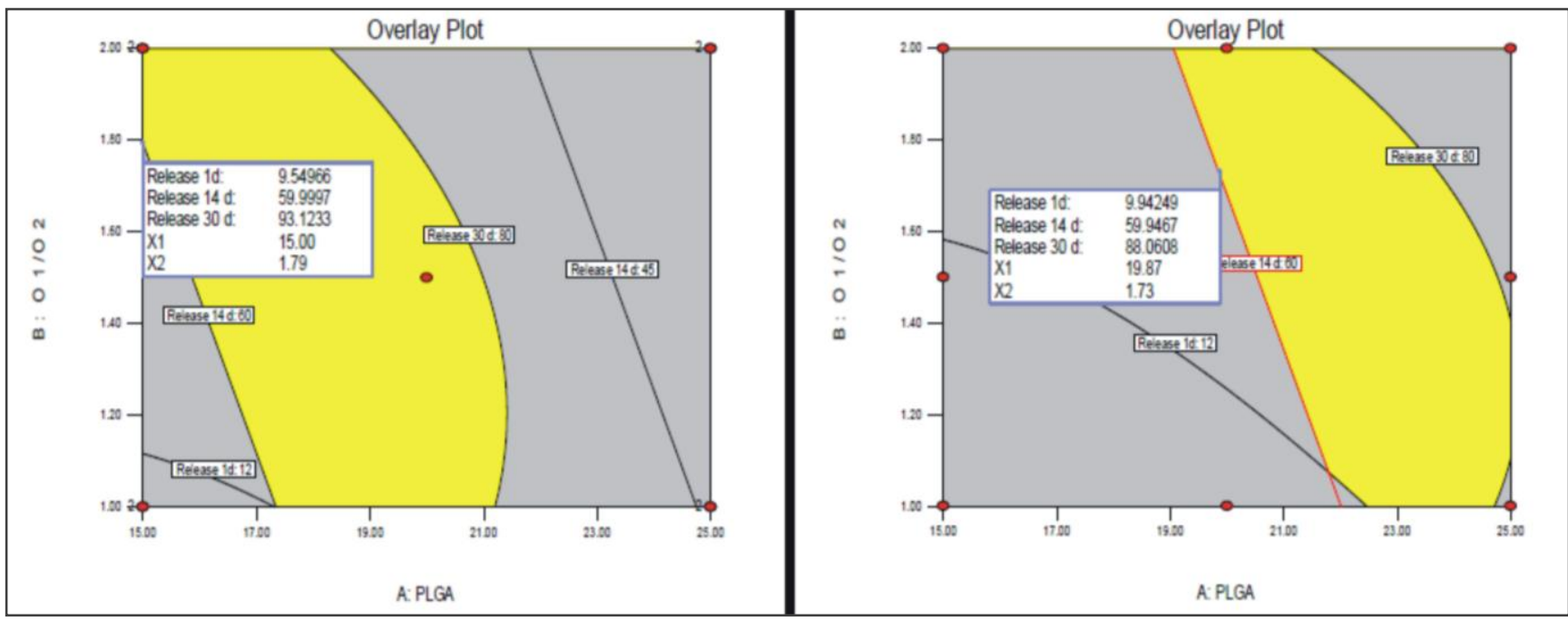

Fig. 4(a): Overlay plots to determine optimized deslorelin ISFM formulation; Solution 1 (with BABZ). Fig. 4(b). Overlay plots to determine optimized deslorelin ISFM formulation; Solution 3 (with DMTR).

Table 5: Determination of optimized formulation of deslorelin ISFM by numeric optimization technique.

\begin{tabular}{|c|c|c|c|c|c|c|c|}
\hline \multicolumn{8}{|c|}{ Constraints } \\
\hline \multicolumn{2}{|c|}{ Name } & Goal & $\begin{array}{c}\text { Lower } \\
\text { Limit }\end{array}$ & $\begin{array}{l}\text { Upper } \\
\text { Limit }\end{array}$ & $\begin{array}{c}\text { Lower } \\
\text { Weight }\end{array}$ & $\begin{array}{c}\text { Upper } \\
\text { Weight }\end{array}$ & Importance \\
\hline \multicolumn{2}{|c|}{ A:PLGA concentration } & is in range & 15 & 25 & 1 & 1 & 3 \\
\hline \multicolumn{2}{|c|}{$\mathrm{B}: \mathrm{O}_{1} / \mathrm{O}_{2}$ ratio } & is in range & 1 & 2 & 1 & 1 & 3 \\
\hline \multicolumn{2}{|c|}{ C:Solvent type } & is in range & DMTR & BABZ & 1 & 1 & 3 \\
\hline \multicolumn{2}{|c|}{ Release 1 day } & Minimize & 4.68 & 12 & 1 & 1 & 3 \\
\hline \multicolumn{2}{|c|}{ Release 14 days } & is in range & 45 & 60 & 1 & 1 & 3 \\
\hline \multicolumn{2}{|c|}{$\frac{\text { Release } 30 \text { days }}{\text { Solutions for } 13}$} & Maximize & 80 & 98.09 & 1 & 1 & 3 \\
\hline \multicolumn{8}{|c|}{ Solutions for 13 combinations of categoric factor levels } \\
\hline Number & PLGA (\%) & $\mathrm{O}_{1} / \mathrm{O}_{2}$ ratio & Solvent & Release 1d (\%) & Release 14 d (\%) & Release $30 \mathrm{~d}(\%)$ & Desirability \\
\hline 1 & 15.00 & 1.79 & BABZ & 9.55 & 60.00 & 93.12 & 0.599 \\
\hline 2 & 15.00 & 2.00 & BABZ & 9.17 & 58.77 & 88.98 & 0.531 \\
\hline 3 & 19.87 & 1.73 & DMTR & 9.94 & 59.94 & 88.06 & 0.518 \\
\hline 4 & 20.00 & 2.00 & DMTR & 9.10 & 58.09 & 83.03 & 0.466 \\
\hline
\end{tabular}


Table 6: Composition of the two optimized deslorelin ISFM formulations.

\begin{tabular}{ccc}
\hline Composition & DO1 & DO2 \\
\hline Deslorelin acetate & $1 \mathrm{mg} / 100 \mathrm{mg}$ formulation & $1 \mathrm{mg} / 100 \mathrm{mg}$ formulation \\
PLGA $(75: 25)$ & $15 \%$ (w.r.t. internal phase $)$ & $20 \%$ (w.r.t. internal phase $)$ \\
External : Internal phase $\left(\mathrm{O}_{1} / \mathrm{O}_{2}\right.$ ratio $)$ & $1.8: 1.0$ & $1.7: 1.0$ \\
Internal phase solvent $\left(\mathrm{O}_{2}\right)$ & BABZ & DMTR \\
External phase $\left(\mathrm{O}_{1}\right)$ & Peanut oil $+2.5 \%$ Aluminiummonostearate $+2 \%$ Span 80 & Peanut oil + 2.5\% Aluminiummonostearate+2 \% Span 80 \\
\hline
\end{tabular}

Table 7: Comparative predicted vs experimental values of different response variables for optimized batches.

\begin{tabular}{|c|c|c|c|c|}
\hline $\begin{array}{l}\text { Batch no. } \\
\left(\mathbf{X}_{1}, \mathbf{X}_{2}\right)\end{array}$ & Response & Predicted value & $\begin{array}{l}\text { Experimental value }(n= \\
\text { 3) }\end{array}$ & Percent prediction error \\
\hline \multirow{3}{*}{$\begin{array}{c}\text { DO1 } \\
(15 \%, 1.8, \text { BABZ })\end{array}$} & Release 1 day (\%) & 9.55 & $10.02 \pm 0.40$ & -4.92 \\
\hline & Release 14 days (\%) & 60.00 & $61.72 \pm 1.53$ & -2.87 \\
\hline & Release 30 days $(\%)$ & 93.12 & $95.56 \pm 2.11$ & -2.62 \\
\hline \multirow{3}{*}{$\begin{array}{c}\mathrm{DO} 2 \\
(20 \%, 1.7, \text { DMTR })\end{array}$} & Release 1 day $(\%)$ & 9.94 & $10.31 \pm 0.51$ & -3.72 \\
\hline & Release 14 days (\%) & 59.94 & $58.18 \pm 1.83$ & 2.94 \\
\hline & Release 30 days (\%) & 88.06 & $90.46 \pm 2.68$ & -2.73 \\
\hline
\end{tabular}

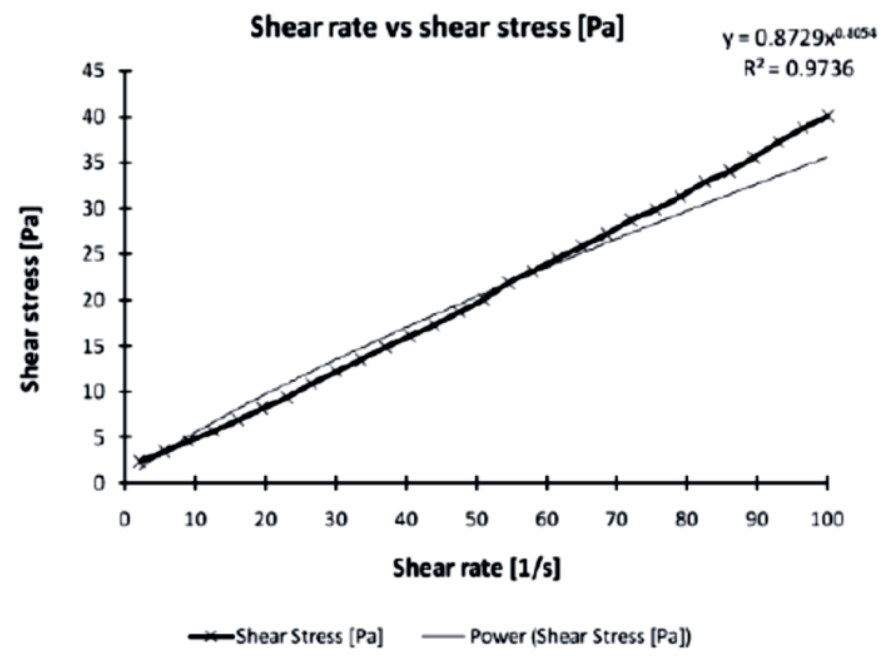

Fig. 5: Rheograms of DO1 deslorelin ISFM formulation shear stress vs shear rate.

\section{Evaluation of optimized deslorelin ISFM formulation Validation of optimized results}

The optimized formulations obtained by numeric and graphical optimization were validated for their performance by preparing three replicates of both the formulations (DO1 and DO2) and determining their release. The contents of formulations DO1 and DO2 are shown in Table 6. Percent prediction error was obtained by comparing predicted results with experimental results. Table 7 shows the actual values, predicted values and percent prediction error of response variables $Y_{1}$ (percent release at 1 day), $Y_{2}$ (percent release at 14 days) and $Y_{3}$ (percent release at 30 days) for DO1 and DO2. From these results, it was observed that formulation DO1 presented faster and most acceptable release rate and pattern. Thus, formulation DO1 containing $15 \%$ PLGA 75:25, 1.8:1 $\mathrm{O}_{1} / \mathrm{O}_{2}$ ratio and $\mathrm{BABZ}(30: 70)$ as the solvent for internal phase was selected as the optimized and validated formulation.

\section{Rheology of ISFM}

The value of viscosity was found to be in the range from 154 to 83 centipoise [cP] on increasing shear rate from 1 to $100 \mathrm{~s}^{-1}$ which showed that on increasing shear rate, viscosity decreases
The average viscosity was found to be $104.79 \pm 25.10 \mathrm{cP}$. Plot of shear stress vs shear rate is shown in Figure 5, also showing power law equation obtained from log shear stress and log shear rate.

Consistency index for DO1 was 7.59 and flow index was 0.8054 . The $\mathrm{R}^{2}$ value for the curve fitting line was found to be 0.9736 which indicates goodness of fit for power law. The power law equation indicated shear thinning or pseudoplastic behavior of the formulation $(n<1)$, which is required for good flow of preparation from a syringe during injection.

\section{Stability of deslorelin in formulation by DSC}

Figures 6 (a), (b) and (c) show DSC thermograms of deslorelin, blank ISFM (without drug) and deslorelin ISFM formulation. The DSC curve for the blank ISFM formulation and drug containing ISFM formulation exhibited an endothermic peak temperature at $52.03^{\circ} \mathrm{C}$ and $52.03^{\circ} \mathrm{C}$ respectively corresponding to the glass transition of PLGA 75:25. No perceptible difference was observed in the peak intensity of PLGA in either case. This showed absence of any chemical interaction between the drug and excipients indicating their compatibility in the formulation. 


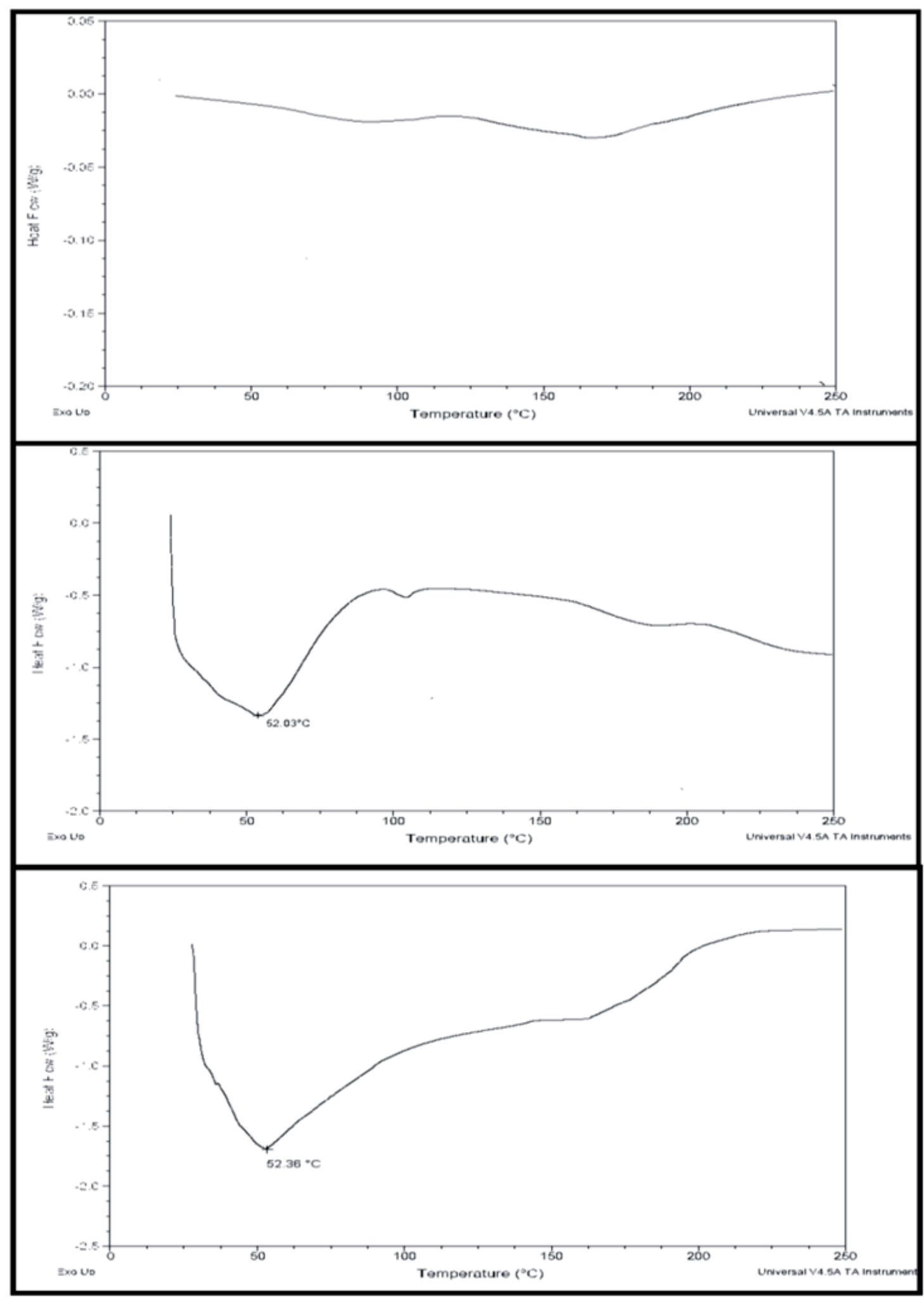

Fig. 6: DSC thermograms of (a) Deslorelin, (b) ISFM without drug and (c) Deslorelin ISFM formulation (DO1). 


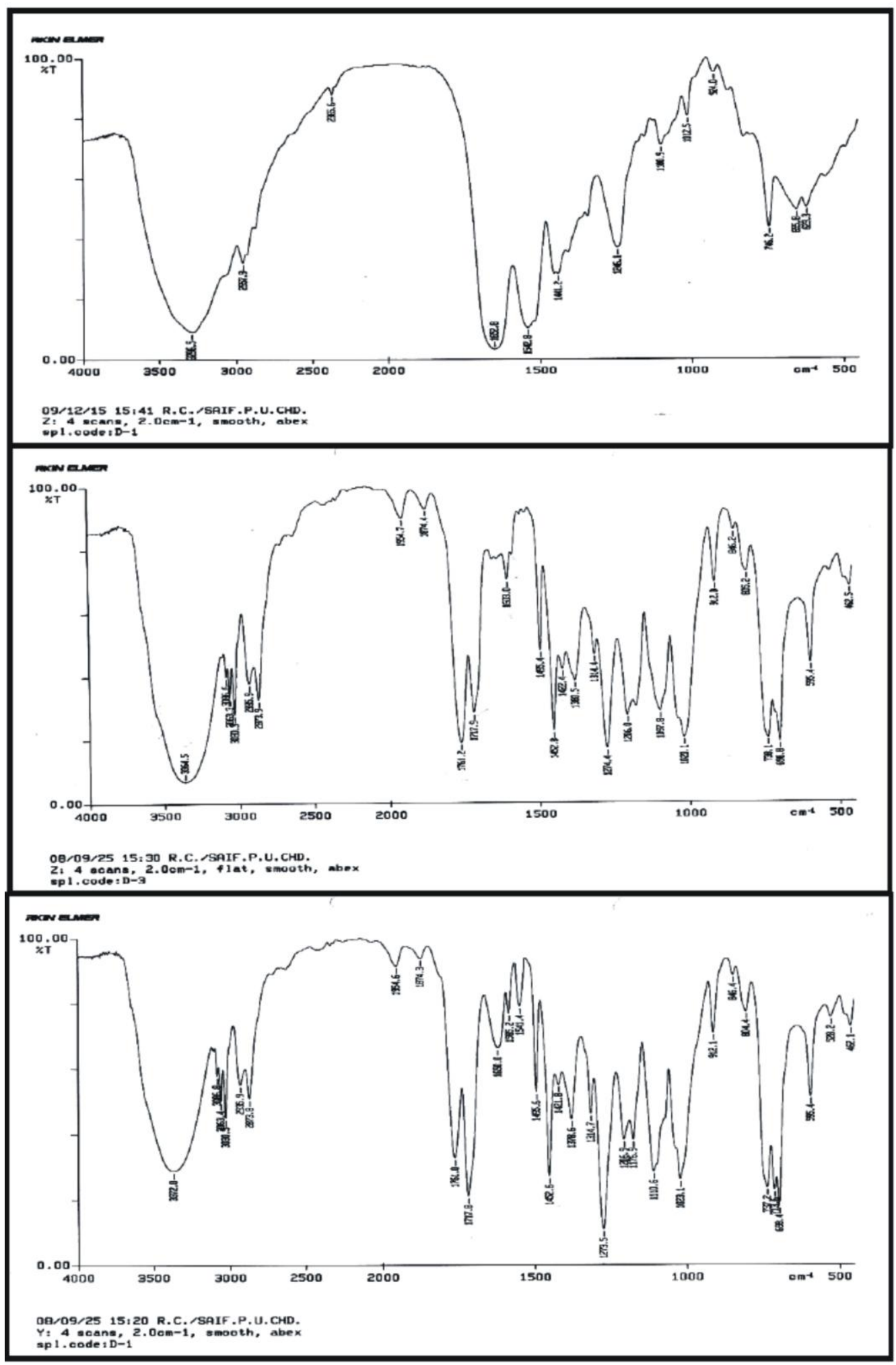

Fig. 7: FTIR spectra of (a) Deslorelin, (b) ISFM without drug and(c) Deslorelin ISFM formulation (DO1).

\section{Stability of deslorelin in ISFM formulations by FTIR}

Figures 7 (a), (b) and (c), depict FTIR spectra of deslorelin, blank ISFM formulation (without drug) and deslorelin ISFM formulation. No major broadening of band or shift in peak was observed indicating no significant structural perturbation.
Conformational stability of deslorelin in ISFM formulations by CD spectroscopy

Figure 8 shows the CD spectra of pure deslorelin, dissolved in $\mathrm{pH} 7.4$ phosphate buffer $(100 \mu \mathrm{g} / \mathrm{mL})$ and in vitro release samples obtained from deslorelin ISFM formulation at the 
end of one-month release study. The CD spectra of freshly prepared deslorelin solution showed maxima at $195 \mathrm{~nm}$ and minima at $218 \mathrm{~nm}$ with a negative shoulder at $203 \mathrm{~nm}$. Conformational stability of the therapeutic protein deslorelin acetate was found to be acceptable when formulated as PLGA based ISFM system. This also indicates the conformational stability of the peptide during the period of release study.

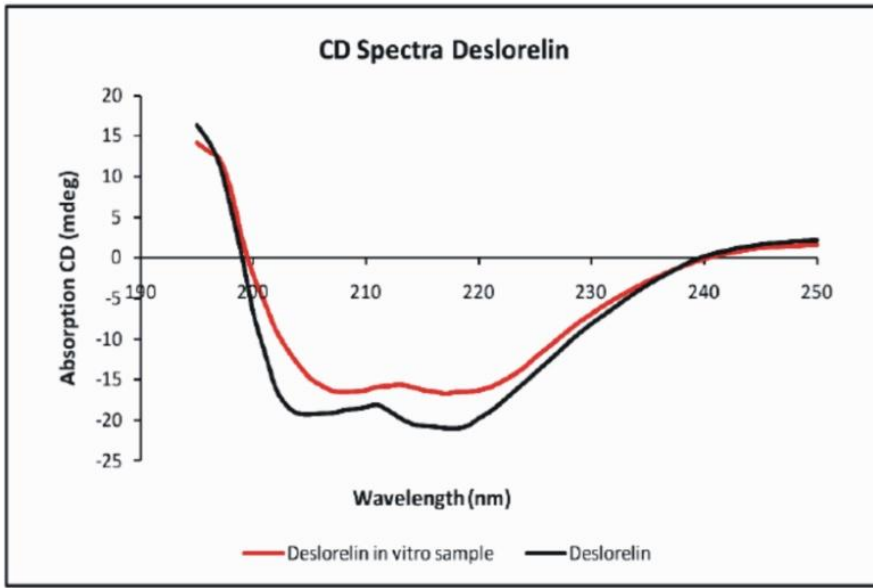

Fig. 8: Comparative, absorption vs wavelength plot obtained from CD Spectroscopy for fresh deslorelin solution in $\mathrm{pH} 7.4$ phosphate buffer and a media sample obtained after 30 days in vitro deslorelin release study.

\section{Drug loading and encapsulation efficiency}

Table 8 shows percent drug loaded and entrapment efficiency of optimized deslorelin ISFM formulation DO1 (3 replicates). The optimized ISFM formulation showed improved entrapment efficiency $(90.78 \pm 1.84)$ and drug loading $(6.05 \pm$ 0.12 ). Due to high molecular weight and high content of polymer in ISFI/ISFM formulations, there was increase in polymeric solution viscosity and molecular weight dependent attraction forces between polymer and protein. In this way, the transfer of protein drug from internal phase to external phase is prevented causing entrapment of more protein.

Table 8: Drug loading and entrapment efficiency of optimized deslorelin ISFM formulation (DO1)

\begin{tabular}{ccc}
\hline S. no. & Drug loading $(\boldsymbol{\%})(\boldsymbol{n}=\mathbf{3})$ & $\begin{array}{c}\text { Entrapment efficiency }(\boldsymbol{\%}) \\
(\boldsymbol{n}=\mathbf{3})\end{array}$ \\
\hline 1 & 5.93 & 89.00 \\
2 & 6.18 & 92.67 \\
3 & 6.04 & 90.67 \\
Mean & $6.05 \pm 0.12$ & $90.78 \pm 1.84$ \\
\hline
\end{tabular}

\section{Particle size distribution and surface morphology of ISFM formulations}

The particle size distribution of deslorelin ISFM was determined by Malvern Mastersizer. The particle size distribution graph of optimized formulation is shown in Figure 9. For drug loaded microspheres, $d_{50}$ value was found to be $16.219 \mu \mathrm{m}, d_{90}$ value was $50.06 \mu \mathrm{m}$ and particle size range was between $1.45 \mu \mathrm{m}$ $-275.42 \mu \mathrm{m}$.As seen in the figure, drug loaded particles presented uniform and normal distribution. For unloaded microspheres, $d_{50}$ value was found to be $13.651 \mu \mathrm{m}, d_{90}$ value was $52.27 \mu \mathrm{m}$ and particle size range was between $1.66 \mu \mathrm{m}-208.42 \mu \mathrm{m}$.

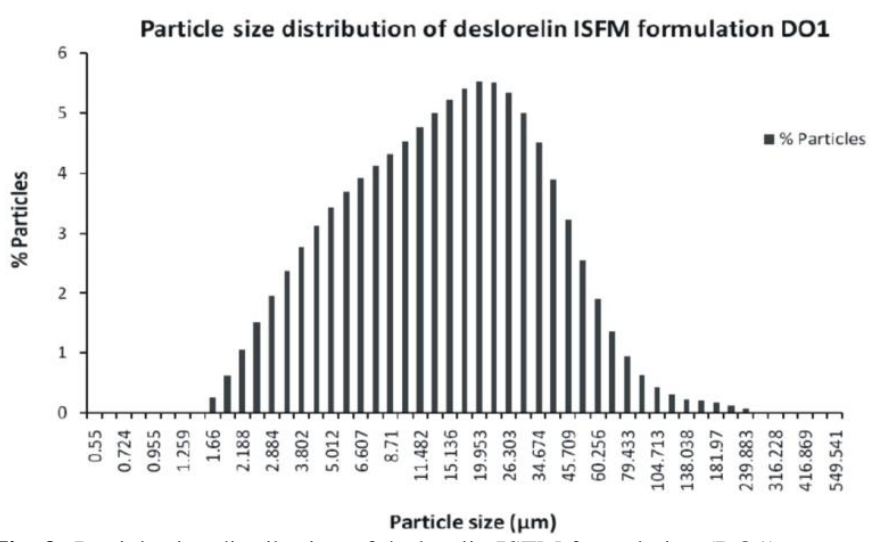

Fig. 9: Particle size distribution of deslorelin ISFM formulation (DO1).

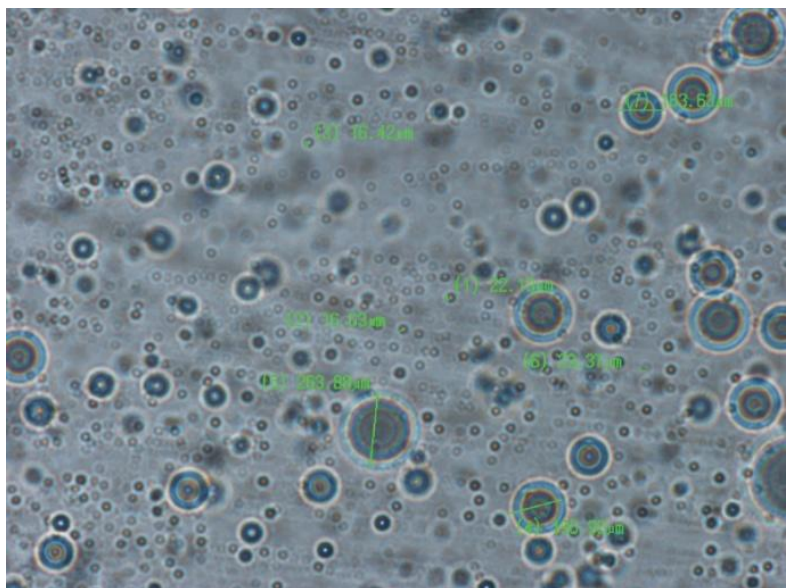

Fig. 10 (a): Photomicrograph of deslorelin ISFM (microglobules) taken by optical microscope (40x).

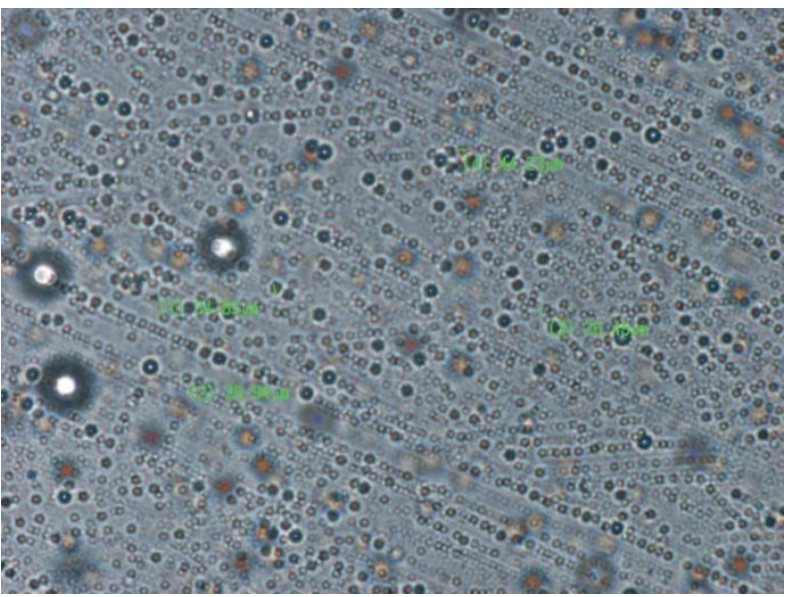

Fig. 10 (b): Photomicrograph of deslorelin ISFM (formed and dried) taken by optical microscope $(40 \mathrm{x})$

Figure 10(a) and 10(b) depicts the optical photomicrographs of deslorelin ISFM formulation DO1. It was observed in Figure 10(a) that the microglobules were spherical and non-aggregated with a distinct boundary separating internal phase with external phase. At this stage these microglobules are also 
known as "embryonic microspheres" that convert to solid microspheres in aqueous environment. It was interesting to find that some particles were still in their embryonic stage and had not yet converted to solid microspheres. During particle size distribution analysis it was noted that the particle size range also included particles smaller than $10 \mu \mathrm{m}$ so TEM analysis was carried out to study the particle morphology.

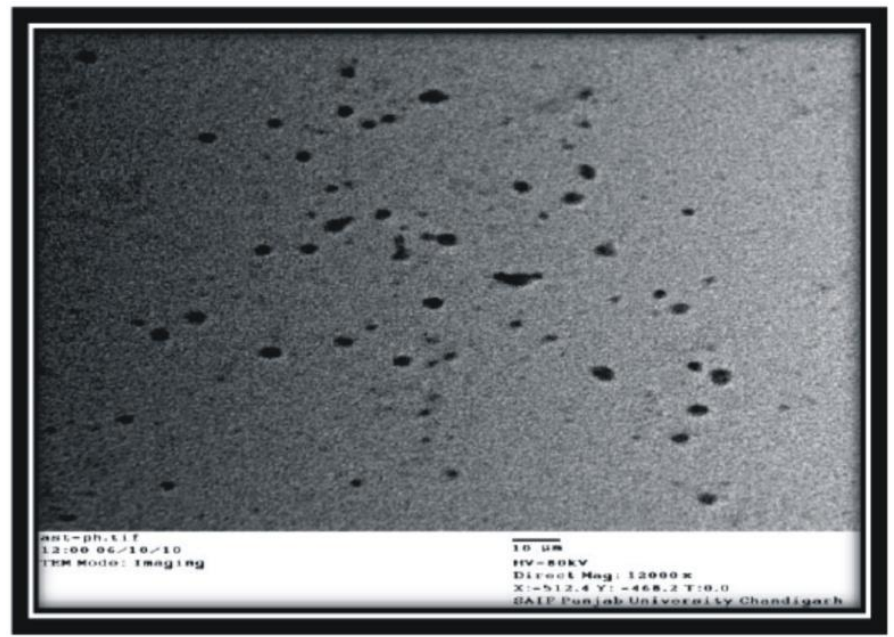

Fig. 11: TEM photomicrographs of deslorelin ISFM formulation DO1

Figure 11 shows the TEM image of formed, isolated and dried deslorelin ISFM. The particles were found to be smaller than $10 \mu \mathrm{m}$, spherical in shape and with some aggregated groups.

\section{Stability studies}

It was observed that after $0,1,3$ and 6 months of storage at both $25^{\circ} \mathrm{C} \pm 2{ }^{\circ} \mathrm{C} / 60 \% \pm 5 \% \mathrm{RH}$ and at $5^{\circ} \mathrm{C} \pm 2^{\circ} \mathrm{C}$ storage conditions, there was no change in appearance, odor or consistency of the optimized deslorelin ISFM formulation DO1. Figure 12 and 13 show drug release profiles of the optimized deslorelin ISFM formulation DO1 stored at both $25^{\circ} \mathrm{C} \pm 2^{\circ} \mathrm{C} / 60 \%$ $\pm 5 \% \mathrm{RH}$ and at $5^{\circ} \mathrm{C} \pm 2^{\circ} \mathrm{C}$ storage conditions. Figure 14 and Table 9 show the percent residual drug and viscosity of the formulations evaluated at different time points. The highest drug release at 6 months was $97.91 \%$, from the formulations stored at $5^{\circ} \mathrm{C} \pm 2^{\circ} \mathrm{C}$ and $96.02 \%$ from those stored at $25^{\circ} \mathrm{C} \pm 2^{\circ} \mathrm{C} / 60 \% \pm$ $5 \% \mathrm{RH}$. The difference was insignificant as it was within $\pm 5 \%$ variation range indicating the stability of the formulation at both the storage conditions.

Table 9: Different parameters evaluated at different time points to determine the stability of deslorelin ISFM systems

\begin{tabular}{ccccc}
\hline $\begin{array}{c}\text { Time } \\
\text { (months) }\end{array}$ & \multicolumn{2}{c}{$\mathbf{2 5}^{\circ} \mathbf{C} \pm \mathbf{2}^{\circ} \mathbf{C} / \mathbf{6 0 \%} \pm \mathbf{5 \%} \mathbf{R H}$} & \multicolumn{2}{c}{$\mathbf{5}^{\circ} \mathbf{C} \pm \mathbf{2}^{\circ} \mathbf{C}$} \\
\cline { 2 - 5 } & $\begin{array}{c}\text { Residual } \\
\mathbf{d r u g}(\%)\end{array}$ & $\begin{array}{c}\text { Viscosity } \\
(\mathbf{c P})(\mathbf{n}=\mathbf{3})\end{array}$ & $\begin{array}{c}\text { Residual } \\
\mathbf{d r u g}(\%) \\
(\mathbf{n = 3})\end{array}$ & $\begin{array}{c}\text { Viscosity } \\
(\mathbf{c P})(\mathbf{n}=\mathbf{3})\end{array}$ \\
\hline 0 & 100 & $125 \pm 2.34$ & 100 & $110 \pm 1.97$ \\
1 & $98.66 \pm 0.54$ & $121 \pm 1.48$ & $99.54 \pm 0.48$ & $107 \pm 2.45$ \\
3 & $97.29 \pm 1.02$ & $116 \pm 2.19$ & $98.33 \pm 0.66$ & $105 \pm 2.37$ \\
6 & $96.02 \pm 0.89$ & $112 \pm 1.88$ & $97.91 \pm 0.98$ & $103 \pm 1.72$ \\
\hline
\end{tabular}

Deslorelin ISFM Stability: Drug release $\left(5^{\circ} \mathrm{C} \pm 2^{\circ} \mathrm{C}\right)$

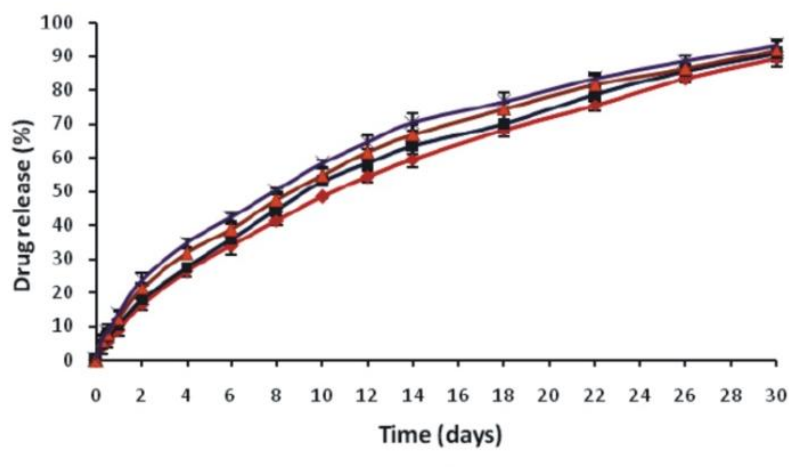

$\longrightarrow 0$ month $\rightarrow-1$ month $\longrightarrow 3$ months $\longrightarrow 6$ months

Fig. 12: Percent release from optimized deslorelin ISFM formulation (DO1) stored at $5^{\circ} \mathrm{C} \pm 2^{\circ} \mathrm{C}$ for $0,1,3$ and 6 months.

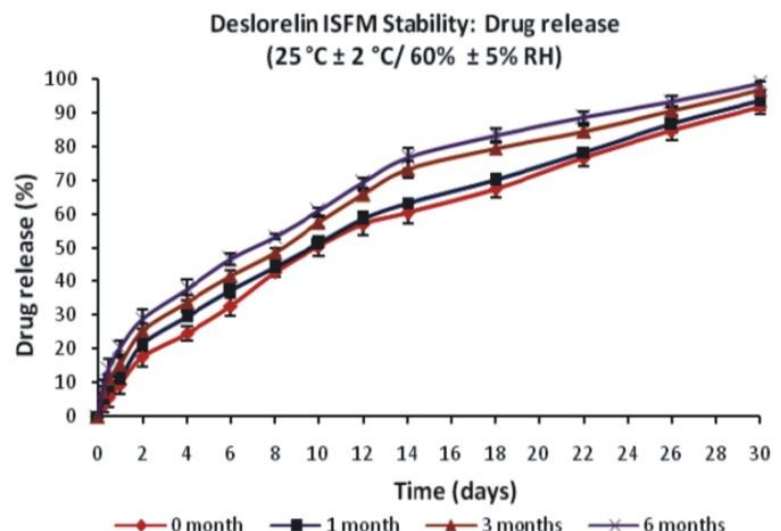

Fig. 13: Percent release from optimized deslorelin ISFM formulation (DO1) stored at $25^{\circ} \mathrm{C} \pm 2{ }^{\circ} \mathrm{C} / 60 \% \mathrm{RH} \pm 5 \% \mathrm{RH} 0,1,3$ and 6 months.

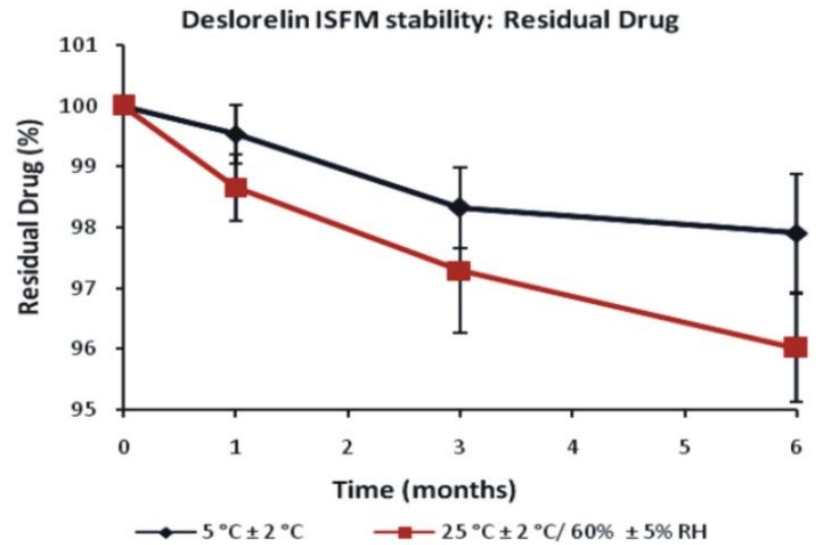

Fig. 14: Percent residual drug vs time plot for optimized deslorelin ISFM formulation (DO1) stored at $5^{\circ} \mathrm{C} \pm 2^{\circ} \mathrm{C}$ and $25^{\circ} \mathrm{C} \pm 2^{\circ} \mathrm{C} / 60 \% \mathrm{RH} \pm 5 \% \mathrm{RH}$.

\section{CONCLUSION}

The present study involved development of ISFM system for deslorelin acetate by applying DoE and optimization techniques. A response surface I-optimal design was used to evaluate the effect of selected factors on the response variables. By analyzing the data and applying numerical as well as graphical optimization techniques, the formulation DO1 with $15 \%$ PLGA (75:25), $\mathrm{O}_{1} / \mathrm{O}_{2}$ ratio of 1:8:1 and $\mathrm{BABZ}$ as internal phase solvent 
was found to be optimized formulation. The results indicated that it was possible to obtain small sized microparticles with desired drug release behaviour from an ISFM system prepared with right combination of excipients in optimized quantities. Further, in vivo pharmacokinetic and pharmacodynamic studies in suitable animal models are required to establish the feasibility of exploring the potential of developed formulation in clinical settings.

\section{ACKNOWLEDGEMENT}

Project Grant (No. 01(2093)/06/EMR-II) provided by CSIR, New Delhi to SanjuDhawan is gratefully acknowledged. Senior research fellowship provided by CSIR, New Delhi and project fellowship by IPCA laboratories to Deepak N. Kapoor is gratefully acknowledged. The authors are grateful to Prof. Bhupinder Singh, UIPS, Panjab University, Chandigarh, for his advice on optimization studies.

Conflict of Interest: The authors declare that there is no conflict of interest.

\section{REFERENCES}

Al-Tahami, K., Meyer, A. and Singh, J. Poly lactic acid based injectable delivery systems for controlled release of a model protein, lysozyme. Pharmaceutical development and technology, 2006; 11(1):7986.

Antony J. 2003. Design of Experiments for Engineers and Scientists. Maryland Heights, MO, USA: Elsevier Science and Technology Books.

Arslanoglu I, Saka N, Bundak R, Gunoz H, Darendeliler F. A comparison of the use of premixed insulins in pen-injectors with conventional patient-mixed insulin treatment in children and adolescents with IDDM. Is there a decreased risk of night hypoglycemia? J PediatrEndocrinolMetab,2000;13:313-18.

Bansal, A., Kapoor, D., Kapil, R., Chhabra, N. and Dhawan, S. Design and development of paclitaxel-loaded bovine serum albumin nanoparticles for brain targeting. ActaPharmaceutica, 2011;61(2):141-156.

Chrisp P, Goa KL. Nafarelin-a review of its pharmacodynamic and pharmacokinetic properties, and clinical potential in sex hormonerelated conditions. Drugs, 1990;39:523-51.

Cleland JL, Daughtery A, Mrsny R. Emerging protein delivery methods. CurrOpinBiotechnol,2001;12:212-9.

Conn PM, Crowley WF. Gonadotropin releasing hormone and its analogues. N Engl J Med, 1991;324:93-103.

Dhawan, S., Kapil, R., Kapoor, D.N. and Kumar, M. Development and evaluation of in situ gel forming system for sustained delivery of cyclosporine. Current drug delivery, 2009; 6(5):495-504.

Dhawan, S., Kapil, R. and Kapoor, D.N. Development and evaluation of in situ gel-forming system for sustained delivery of insulin. Journal of biomaterials applications, 2011;25(7):699-720.

Fu K, Klibanov AM, Langer R. Protein stability in controlledrelease systems. Nature Biotech, 2000;18:24-5.

Gudmundsson JA, Nillius SJ, Bergquist C. Inhibition of ovulation by intranasal nafarelin-a new superactive agonist of GnRH. Contraception, 1984;30:107-14.

Higuchi T. Mechanism of sustained action medication: theoretical analysis of rate of release of solid drugs dispersed in solid matrices. J Pharm Sci, 1963;52:1145-9.

ICHQ1F. Explanatory note on the withdrawal of ICH Q1F for the ICH website. Geneva, Switzerland: International Conference on Harmonization; 2006 [updated 2006; cited accessed December 2010]; Available at: http://www.ich.org/products/guidelines.html.
Jain R, Shah NH, Malick AW, Rhodes CT. Controlled drug delivery by biodegradable poly(ester) devices: Different preparative approaches. Drug Development and Industrial Pharmacy, 1998;24(8):70327.

Jain RA, Rhodes CT, Railkar AM, Malick AW, Shah NA. Controlled release of drugs from injectable in-situ formed biodegradable PLGA microspheres: effect of various formulation variables. Eur J Pharm Biopharm, 2000;50:257-62.

Jain RA, Rhodes CT, Railkar AM, Malick AW, Shah NH. Comparison of various injectable protein loaded biodegradable poly (lactide-co-glycolide) (PLGA) devices: in-situ formed implant vsin-situ formed microspheres vs isolated microspheres. Pharmaceutical Development and Technology, 2000; 5(2): 201-7.

Kapil, R., Dhawan, S., Beg, S. and Singh, B. Buccoadhesive films for once-a-day administration of rivastigmine: systematic formulation development and pharmacokinetic evaluation. Drug development and industrial pharmacy, 2013; 39(3):466-480.

Kapil R, Dhawan S, Singh B. Development and validation of a spectrofluorimetric method for the estimation of rivastigmine in formulations. Indian Journal of Pharmaceutical Sciences, 2009;71(5):581 5 .

Kapil R, Kapoor DN, Dhawan S. Flow, compressive, and bioadhesive properties of various blends of poly(ethylene oxide). Drug DevInd Pharm, 2009.

Kapoor, D.N., Katare, O.P. and Dhawan, S. In situ forming implant for controlled delivery of an anti-HIV fusion inhibitor. International journal of pharmaceutics, 2012; 426(1):132-143.

Kiesel LA, Rody A, Greb RR, Szilagyi A. Clinical use of GnRH analogues. ClinEndocrinol (Oxf), 2002;56:677-87.

Kompella, UB, Dani, BA. Metabolism of [DES-GLY 10, DTRP 6] LHRH ethylamide in rabbit nasal tissue. Life sciences, 1996; 58(24): 2201-2207.

Kompella, UB,Dani, BA. Metabolism of [des-Gly10, D-Trp6] LHRH ethylamide in the rabbit conjunctiva. Journal of ocular pharmacology and therapeutics, 1997; 13(2): 163-170.

Korsemeyer RW, Gurny R, Doelker E, Buri P, Peppas NA. Mechanisms of solute release from porous hydrophilic polymers International Journal of Pharmaceutics, 1983;15:25-35.

Koushik K, Dhanda DS, Cheruvu NP, Kompella UB. Pulmonary delivery of deslorelin: large-porous PLGA particles and HPbetaCD complexes. Pharm Res, 2004;21(7):1119-26.

Kranz H, Bodmeier R. A novel in-situ forming drug delivery system for controlled parenteral drug delivery. International Journal of Pharmaceutics, 2007;332(1-2):107-14.

Kranz H, Yilmaz E, Brazeau GA, Bodmeier R. In vitro and in vivo drug release from a novel in-situ forming drug delivery system. Pharmaceutical research, 2008; 25(6): 1347-1354.

Luan X, Bodmeier R. Influence of the poly(lactide-coglycolide) type on the leuprolide release from in-situ forming microparticle systems. Journal of Controlled Release, 2006;110(2):266-72.

Luan, X. and Bodmeier, R. In situ forming microparticle system for controlled delivery of leuprolide acetate: influence of the formulation and processing parameters. European journal of pharmaceutical sciences, 2006;27(2):143-149.

Oberye J, Mannaerts B, Huisman J, Timmer C. Local tolerance, pharmacokinetics, and dynamics of ganirelix (Orgalutran) administration by Medi-Jector compared to conventional needle injections. Hum Reprod, 2000;15:245-49.

Okuma FW, Daugherty A, Dao L, Filder PJ, Brooks D, Sane S, et al., editors. Sustained delivery of growth hormone from a novel injectable liquid. PLAD Proceed Intern Symp Control Rel Blood Maser; 2001.

Peppas NA, Sahlin JJ. A simple equation for the description of solute release (III): coupling of diffusion and relaxation. International Journal of Pharmaceutics, 1989;57:169-72.

Plaizier-Vercammen JA, Lecluse E, Boute P. Rheological properties of topical fluoride gels. Dent Mater, 1989;5(5):301-5. 
Ravivarapu HB, Moyer KL, Dunn RL. Sustained activity and release of leuprolide acetate from an in-situ forming polymeric implant. PharmaSciTechnol, 2000;1:1-8.

Robinson SN, Talmadge JE. Sustained release of growth factors. In Vivo, 2002;16:535-40.

Shen ZY, Ma GH, Dobashi T, Maki Y, Su ZG. Preparation and characterization of thermo-responsive. International Journal of Pharmaceutics, 2008; 346:133-142.

Singh B. and Singh S. "A comprehensive computer program for the study of drug release kinetics from compressed matrices." Indian Journal of Pharmaceutical Sciences, 1998; 60 (6): 358-362.

Singh B, Kumar R, Ahuja N. Optimizing drug delivery systems using systematic "Design of Experiments" Part I: Fundamental Aspects. Critical Reviews in Therapeutic Drug Carrier Systems, 2004;22(1):27-105.

Stat-Ease. Design Expert ${ }^{\circledR}$ v 8.0.1. v 8.0.1 (Trial version) ed. Minneapolis, MN, USA: Stat-Ease, Inc.; 2010.

Suprelorin: Scientific Discussion (INN: Deslorelin Acetate) [database on the Internet]. Committee for Medicinal Products for Veterinary Use (CVMP), European Medicines Evaluation Agency (EMEA). 2002 [cited December 2010]. Available at: www.ema.europa.eu.
WHO. Stability testing of active pharmaceutical ingredients and finished pharmaceutical products. Geneva: World Health Organization; 2009.

Wood GC, Iyer MR, Geller AM, Fleischner AM, Sheth BB. A high pressure liquid chromatography assay method for analysis of deslorelin and benzyl alcohol in deslorelin injection. Journal of liquid chromatography \& related technologies, 1998; 21(14):2183-2190.

Zhang, Z., Shousheng, X.I.E., Jinhai, H.U., Zhuoguang, M.I.A.O. and Lei, W.A.N.G. Assembly Variation Identification of High Pressure Spool by Response Surface Based Model Updating Using IVoptimal Designs. Chinese Journal of Aeronautics, 2012; 25(5), pp.817824.

\section{How to cite this article:}

Kapoor DN, Katare OP, Kaurav H, Dhawan S. Development and optimization of in-situ forming microparticles for long term controlled delivery of deslorelin acetate. J App Pharm Sci, 2018; 8 (01): 59-72. 